\title{
The patterns of lifestyle, metabolic status, and obesity among hypertensive Korean patients: a latent class analysis
}

\author{
Suyoung Kim, Seon Cho, Eun-Hee Nah \\ Health Promotion Research Institute, Korea Association of Health Promotion, Seoul, Korea
}

OBJECTIVES: This study aimed to identify latent classes in hypertensive patients based on the clustering of factors including lifestyle risk factors, metabolic risk factors, and obesity in each sex.

METHODS: This cross-sectional study included 102,780 male and 103,710 female hypertensive patients who underwent health check-ups at 16 centers in Korea, in 2018. A latent class analysis approach was used to identify subgroups of hypertensive patients. Multinomial logistic regression was performed to examine the association between latent classes and comorbidities of hypertension.

RESULTS: A four-class model provided the best fit for each sex. The following latent classes were identified: Class I (male: 16.9\%, female: 1.7\%; high risk of lifestyle behaviors [HB] with metabolic disorders and obesity [MO]), Class II (male: $32.4 \%$, female: 47.1\%; low risk of lifestyle behaviors [LB] with MO), Class III (male: 15.3\%, female: 1.8\%; HB with metabolic disorders and normal weight [MNW]), Class IV (male: 35.5\%, female: 49.4\%; LB with MNW). Lifestyle patterns in the latent classes were classified as high-risk or low-risk according to smoking and high-risk drinking among male, and presented complex patterns including physical inactivity alone or in combination with other factors, among female. Stage 2 hypertensive or diabetic individuals were likely to belong to classes including obesity (HB-MO, LB-MO) in both sexes, and additionally belonged to the HB-MNW class in male.

CONCLUSIONS: Metabolic disorders were included in all latent classes, with or without lifestyle risk factors and obesity. Hypertensive females need to manage obesity, and hypertensive males need to manage lifestyle risk factors and obesity. Sex-specific lifestyle behaviors are important for controlling hypertension.

KEY WORDS: Hypertension, Life style, Obesity, Metabolic diseases, Latent class analysis

\section{INTRODUCTION}

According to the World Health Organization (WHO), the prevalence of hypertension (HTN) worldwide is $25 \%$ in male and $20 \%$

\section{Correspondence: Eun-Hee Nah}

Health Promotion Research Institute, Korea Association of Health Promotion, 396 Gonghang-daero, Gangseo-gu, Seoul 07649, Korea E-mail: cellonah@hanmail.net

Received: Jun 30, 2020 / Accepted: Aug 31, 2020 / Published: Aug 31, 2020

This article is available from: https://e-epih.org/

(c) This is an open-access article distributed under the terms of the Creative Commons Attribution License (https://creativecommons.org/licenses/by/4.0/), which permits unrestricted use, distribution, and reproduction in any medium, provided the original work is properly cited.

(C) 2020, Korean Society of Epidemiology in female; less than $20 \%$ of these individuals manage their HTN [1]. High blood pressure (BP) is a major risk factor for cardio-cerebrovascular disease and chronic kidney disease, is commonly accompanied by diabetes, liver disease, and cancer (which complicates disease treatment $[2,3]$ ), and is a major cause of premature death. Thus, management of high $\mathrm{BP}$ is important to prevent disease and lower disease mortality.

Management of BP by lifestyle improvement is recommended and as a supplementary treatment method for the early treatment of hypertensive patients [4]. In intervention studies on stage 1 hypertensive patients, reduction in mean $\mathrm{BP}$ and management of HTN were confirmed after lifestyle improvements, in line with other similar studies [4-6]. Modified health behaviors in BP management include heavy drinking, smoking, inadequate physical activity (PA), and excess salt consumption. Other demographic 
factors such as sex, age, and race, and metabolic status including obesity are also important in managing high BP [5-8]. Metabolic abnormalities and obesity are important components of the metabolic syndrome along with HTN, and mutual influences should be considered in determining HTN risk.

Lifestyle risk factors appear clustered in individuals, and the combination of risk factors may have synergistic effects on disease occurrence. Therefore, an approach based on multiple behavioral characteristics is important in disease management [6,9]. Previous studies on management of HTN have considered the clustered pattern of lifestyle behaviors, and all risk behaviors were numbered/ scored or defined as all possible combinations $[6,9,10]$. However, this complicates interpretation of the results, and has limitations in identifying specific lifestyle factors/patterns. For effective HTN management, it is necessary to seek measures that reflect the homogeneous characteristics as well as the individual influences of the related factors. Latent class analysis (LCA) provides useful information to analyze the clustered characteristics of health risk behaviors. This is used to cluster the subjects to identify homogeneous and mutually exclusive subgroups that exist within subject groups. This method reduces and summarizes multiple categorial data.

LCA provides more information about health status and lifestyle behaviors, which help to identify preventive effect to improve prognosis in subjects with disease [11]. LCA was applied for the purpose of high BP management in studies by Ghanbari et al. [12] who studied obesity and lifestyle patterns of hypertensive patients, and by Trivedi et al. [13] who have assessed adherence patterns in patients, focusing on the hypertensive guidelines. In these studies, latent classes were classified based on lifestyle behaviors and obesity, but not metabolic status. Metabolic abnormalities and obesity play an important role in elevating BP. Hypertensive patients with metabolic abnormalities show changes in cardiovascular or renal function in the preclinical stage, which increase the risk of related diseases [14]. Therefore, it is necessary to analyze the patterns considering lifestyle and metabolic state for BP management.

In this study, LCA was conducted to identify latent classes of hypertensive patients's risk factors based on lifestyle, obesity, and metabolic status. Characteristics such as age, anthropometric measurements, clinical factors, and disease history were presented, and the distributions of comorbid diseases such as stage 2 HTN, diabetes, and renal and liver function abnormalities were compared by identified subgroups.

\section{MATERIALS AND METHODS}

\section{Research subjects}

This cross-sectional study included hypertensive patients aged $>40$ years who visited 16 health check-up centers in 13 regions of Korea from January 2018 to December 2018. This study included those who were diagnosed with HTN, were taking anti-hypertensive drugs at the interview, or had a systolic blood pressure (SBP) of $>140 \mathrm{mmHg} / \mathrm{a}$ diastolic blood pressure (DBP) of $>90 \mathrm{mmHg}$ [15]. Among those who completed the consent form, non-Korean or individuals who did not complete the questionnaire survey or clinical examination items for the study were excluded. A total of 206,490 subjects were selected (Figure 1).

\section{Latent class indicators and covariates}

Latent class indicators were lifestyle including uncontrolled BP, smoking, high-risk drinking, insufficient PA, and obesity and metabolic abnormalities. Uncontrolled BP was defined as SBP

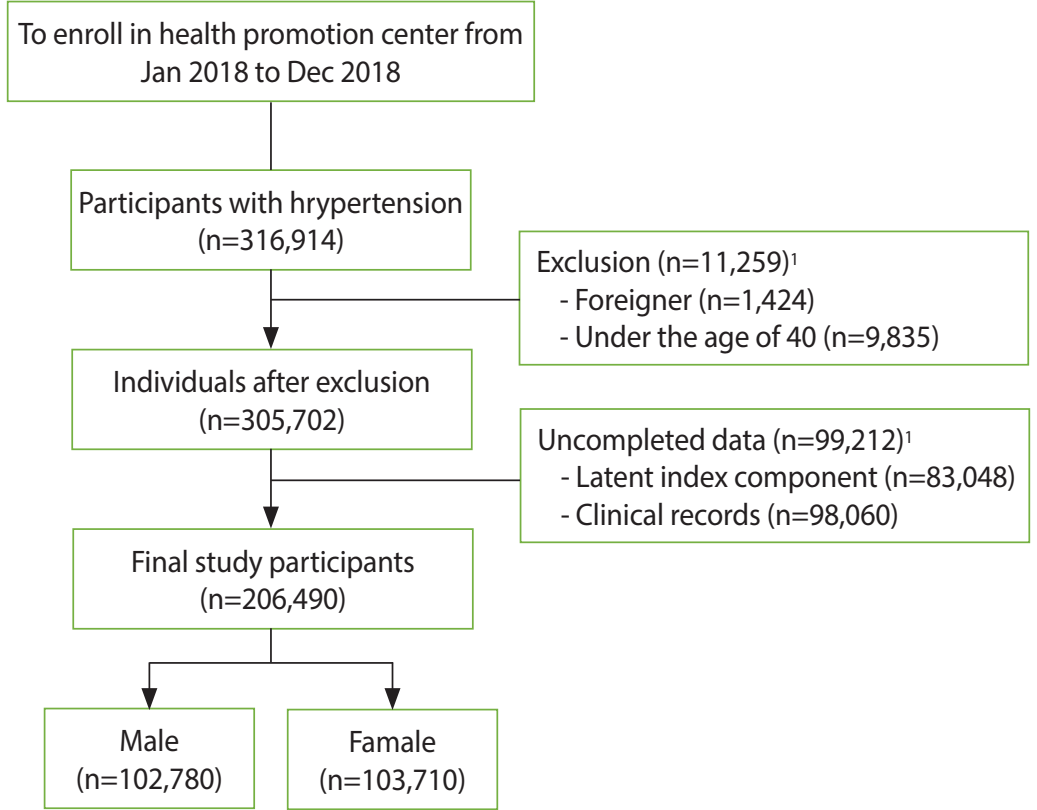

Figure 1. Flow diagram for study participants. 'Individuals after duplicate removed. 
$>140 \mathrm{mmHg} / \mathrm{DBP}>90 \mathrm{mmHg}$. A smoking status was defined as past or current smoker. High-risk drinking was defined as consumption of 7 glasses and 5 glasses of alcohol per time for male and female respectively, and more than twice a week [16]. According to the WHO standard, one minute of vigorous PA was equated to two minutes of moderate PA. Insufficient PA was designated if the total PA time per week was less than 150 minutes [17]. Obesity (body mass index [BMI] $\geq 25 \mathrm{~kg} / \mathrm{m}^{2}$ ) and abdominal obesity (waist circumference $\geq 90 \mathrm{~cm}$ in male and $\geq 85 \mathrm{~cm}$ in female) were considered for obesity status. One or more of high triglycerides ( $\geq 150 \mathrm{mg} / \mathrm{dL}$ ), low high-density lipoprotein (HDL) cholesterol (male: $<40 \mathrm{mg} / \mathrm{dL}$; female: $<50 \mathrm{mg} / \mathrm{dL}$ ), and high fasting blood glucose ( $\geq 100 \mathrm{mg} / \mathrm{dL}$ ) were used to designate metabolic abnormality using National Cholesterol Education Program Adult Treatment Panel III.

Age, history of cardiovascular disease, anti-hypertensive drug use, and family history of HTN were considered as covariates for the identified classes based on answers to a health questionnaire, Stage $2 \mathrm{HTN}$ (SBP $\geq 160 \mathrm{mmHg} / \mathrm{DBP} \geq 100 \mathrm{mmHg}$ ), diabetes, and renal and liver dysfunction were included as comorbidities in the latent class. Diabetes mellitus was defined as diagnosis of diabetes, taking antidiabetic drugs or a fasting blood glucose level $\geq 126 \mathrm{mg} / \mathrm{dL}$. Renal dysfunction was defined serum creatinine $>1.5 \mathrm{mg} / \mathrm{dL}$, estimated glomerular filtration rate (e-GFR) $<60 \mathrm{~mL} / \mathrm{min} / 1.73 \mathrm{~m}^{2}$, or urine protein $\geq 1+$. Liver dysfunction was defined aspartate transaminase (AST) $\geq 51 \mathrm{IU} / \mathrm{L}$, alanine transaminase (ALT) $\geq 46$ IU/L or gamma-glutamyl transpeptidase $(\gamma$-GTP) $\geq 78 \mathrm{IU} / \mathrm{L}$ in male/ $\geq 46 \mathrm{IU} / \mathrm{L}$ in female.

\section{Anthropometric measurements and clinical examinations}

$\mathrm{BP}$ was measured with an automatic sphygmomanometer. In the case of SBP $\geq 140 \mathrm{mmHg} / \mathrm{DBP} \geq 90 \mathrm{mmHg}$, re-measurements were performed using an aneroid manual sphygmomanometer in accordance with the national health examination standards. BMI was calculated as weight $(\mathrm{kg}) /$ height $(\mathrm{m})^{2}$ using an automatic body measuring instrument.

Blood chemistry tests for fasting blood glucose, triglycerides, HDL cholesterol, low-density lipoprotein (LDL) cholesterol. AST, ALT, $\gamma$-GTP, and serum creatinine were measured by an enzyme method using the Hitachi 7600 (Hitachi, Nakai, Japan). GFR was calculated by the Modification of Diet in Renal Disease equation, and the urine protein level was measured by the dip-and-read method.

\section{Statistical analysis}

The number of latent classes was determined by LCA, using 7 latent class indicators, and each class was classified based on the probability of each indicator. To determine the optimal number of latent classes, model fit of each latent class was sequentially compared while progressively increasing the number of classes. Akaike information criterion (AIC), Bayesian information criterion (BIC), consistent AIC, and adjusted BIC were comprehensively evaluated for model fit, and a lower value represented a better fit. In addition, entropy was presented to assess the precision of classifying latent class membership in each model; an entropy value closer to 1 indicated a greater precision of classification. The optimal number of latent classes was selected by considering the goodness-of-fit and entropy, the probability ( $>1 \%)$ that each class contains an entity, interpretability and parsimony [18].

Analysis of variance, t-test, and chi-square tests were performed according to the data type to compare characteristics by sex or derived latent classes. The Scheffe's method was used for post-hoc testing. A multinomial logistic regression analysis was performed with the low-risk class as the reference in the derived latent class, and the relationship with the state of comorbid diseases was estimated. The SAS version 9.4 (SAS Institute Inc., Cary, NC, USA) program was used for analysis, and the significance level was set to 0.05 .

\section{Ethics statement}

This study was conducted with the approval of the Institutional Review Board (IRB) of the Korea Association of Health Promotion (IRB No. 130750-201907-HR-020). Informed consent was confirmed by the IRB.

\section{RESULTS}

\section{Clinical and disease history characteristics according to sex}

Among the study population, $49.8 \%$ were male, and $50.2 \%$ were female. Anthropometric measurements excluding SBP, clinical tests, and disease history characteristics showed significant sexrelated differences. The mean age was higher in female $(61.9 \pm$ 10.5 vs. $64.6 \pm 9.2$ years), and clinical tests excluding cholesterol level and anthropometric measurements were generally at a higher level in male. A family history of HTN was more frequently observed in female than in male ( 29.2 vs. $34.2 \%)$; history of disease was higher in male than in female (10.3 vs. $7.7 \%$ ) (Table 1$)$.

All latent class indicators showed significant sex-related differences (Table 1), and their levels were higher in male. However, insufficient PA (42.3 vs. $51.7 \%$ ) and abdominal obesity (42.1 vs. $43.2 \%$ ) were higher in female than in male. Smoking, drinking, and insufficient PA showed relatively large sex-related differences $(\mathrm{p}<$ 0.001 for each). To analyze patterns reflecting sex-related differences in lifestyle, obesity, and metabolic status, latent classes were estimated by dividing sex.

\section{Classification of latent classes for risk factors in hypertensive patients}

To classify the latent classes in hypertensive patients, the number of classes was progressively increased to six, and the model fit indexes AIC, BIC, consistent AIC, and adjusted BIC were compared (Table 2). The model fit index for male decreased as more classes were included in the model, and a slow decline was observed beyond a 4-class model. In the 4-class model, the entropy 
Table 1. Characteristics of study subjects according to sex

\begin{tabular}{|c|c|c|c|}
\hline Characteristics & $\begin{array}{c}\text { Male } \\
(n=102,780)\end{array}$ & $\begin{array}{c}\text { Female } \\
(n=103,710)\end{array}$ & $p$-value \\
\hline Age (yr) & $61.9 \pm 10.5$ & $64.6 \pm 9.2$ & $<0.001$ \\
\hline \multicolumn{4}{|l|}{ Anthropometric measurement } \\
\hline $\mathrm{SBP}(\mathrm{mmHg})$ & $132.7 \pm 15.1$ & $132.9 \pm 15.7$ & 0.077 \\
\hline $\mathrm{DBP}(\mathrm{mmHg})$ & $82.3 \pm 10.7$ & $79.9 \pm 10.0$ & $<0.001$ \\
\hline Waist (cm) & $88.7 \pm 13.9$ & $83.8 \pm 11.2$ & $<0.001$ \\
\hline BMI $\left(\mathrm{kg} / \mathrm{m}^{2}\right)$ & $25.6 \pm 3.1$ & $25.5 \pm 3.5$ & $<0.001$ \\
\hline \multicolumn{4}{|l|}{ Clinical factors } \\
\hline TG (mg/dL) & $155.8 \pm 117.9$ & $127 \pm 77.5$ & $<0.001$ \\
\hline HDL cholesterol (mg/dL) & $49.6 \pm 12.0$ & $55.3 \pm 12.8$ & $<0.001$ \\
\hline LDL cholesterol (mg/dL) & $105.6 \pm 35.8$ & $111.8 \pm 36.6$ & $<0.001$ \\
\hline FBS (mg/dL) & $112.9 \pm 30.0$ & $107.1 \pm 26.1$ & $<0.001$ \\
\hline AST (IU/L) & $30.9 \pm 21.7$ & $27.7 \pm 16.6$ & $<0.001$ \\
\hline ALT (IU/L) & $30.4 \pm 25.4$ & $24.0 \pm 19.3$ & $<0.001$ \\
\hline$\gamma$-GTP (IU/L) & $60.4 \pm 88.9$ & $30.8 \pm 40.3$ & $<0.001$ \\
\hline Serum creatinine (mg/dL) & $1.12 \pm 0.38$ & $0.86 \pm 0.27$ & $<0.001$ \\
\hline e-GFR (mL/min/1.73 m²) & $74.9 \pm 15.8$ & $74.5 \pm 15.8$ & $<0.001$ \\
\hline Urine protein (+) & $7,399(7.2)$ & $3,938(3.8)$ & $<0.001$ \\
\hline \multicolumn{4}{|l|}{ History of HTN } \\
\hline No awareness & $18,947(18.4)$ & $15,075(14.5)$ & $<0.001$ \\
\hline Diagnosis & $4,257(4.1)$ & $2,581(2.5)$ & \\
\hline Diagnosis+medication & $79,574(77.4)$ & $86,054(83.0)$ & \\
\hline \multicolumn{4}{|l|}{ History of disease } \\
\hline Overall & $10,567(10.3)$ & $8,026(7.7)$ & $<0.001$ \\
\hline Stroke & $3,746(3.6)$ & $2,870(2.8)$ & $<0.001$ \\
\hline Heart disease & $7,426(7.2)$ & $5,570(5.4)$ & $<0.001$ \\
\hline Family history of HTN & $29,958(29.2)$ & $35,483(34.2)$ & $<0.001$ \\
\hline \multicolumn{4}{|l|}{ Latent class indicators } \\
\hline \multicolumn{4}{|l|}{ Lifestyle behavior } \\
\hline $\begin{array}{l}\text { Uncontrolled blood } \\
\text { pressure }\end{array}$ & $45,286(44.1)$ & $41,918(40.4)$ & $<0.001$ \\
\hline Smoking: past or current & $74,786(72.8)$ & $3,797(3.7)$ & $<0.001$ \\
\hline High-risk alcohol drinking & $33,129(32.2)$ & $3,546(3.4)$ & $<0.001$ \\
\hline Insufficient physical activity & $43,495(42.3)$ & $53,636(51.7)$ & $<0.001$ \\
\hline \multicolumn{4}{|l|}{ Metabolic status } \\
\hline $\begin{array}{l}\text { Metabolic risk } \\
\qquad(\geq 1 \text { component })\end{array}$ & $85,222(82.9)$ & $84,121(81.1)$ & $<0.001$ \\
\hline \multicolumn{4}{|l|}{ Obesity } \\
\hline Obesity & $57,594(56.0)$ & $53,875(52.0)$ & $<0.001$ \\
\hline Abdominal obesity & $43,231(42.1)$ & $44,831(43.2)$ & $<0.001$ \\
\hline
\end{tabular}

Values are presented as mean \pm standard deviation or number (\%). SBP, systolic blood pressure; DBP, diastolic blood pressure; TG, triglycerides; $H D L$, high-density lipoprotein; LDL, low-density lipoprotein; FBS, fasting blood glucose; AST, aspartate transaminase; ALT, alanine transaminase; $\gamma$-GTP, gamma-glutamic transpeptidase; e-GFR, estimated glomerular filtration rate; HTN, hypertension.

was 0.83 , and the probability of membership in each latent class was $>1 \%$. Thus, this was selected as the final model. An inverse relationship between the number of classes and the model fit index was observed for female as well, and a slow decline was ob- served beyond a 5-class model. In the 5-class model, the entropy was 0.74 , and the membership probability was $>1 \%$. However, three of the 5-class were at a low level of $<11 \%$; thus the number of latent classes was reduced. After a comprehensive consideration of the simplicity of the model, convenience of interpretation, and level of entropy, a 4-class model was selected.

Latent class models classified in male and female were categorized based on the response pattern of the indicator variables in each class. The model divided classes considering high-risk/lowrisk lifestyle, metabolic abnormalities, and obesity/normal weight (Table 3). Regarding lifestyle risk level in male, the low-risk subgroups included only smoking and the high-risk subgroups including smoking and high-risk drinking. According to lifestyle risk level, female was classified into a low-risk subgroups that included insufficient PA alone or nothing of all factors, and a highrisk subgroups that included a combination of uncontrolled BP, high-risk drinking, smoking, and insufficient PA. Of the total male participants, $16.9 \%, 32.4 \%, 15.3 \%$, and $35.5 \%$ were classified into high-risk of lifestyle behaviors with metabolic disorders and obesity (HB-MO), low-risk of lifestyle behaviors with metabolic disorders and obesity (LB-MO), high-risk of lifestyle behaviors with metabolic disorders and normal weight (HB-MNW), and low-risk of lifestyle behaviors with metabolic disorders and normal weight (LB-MNW), respectively. Among female participants, $1.7 \%, 47.1 \%, 1.8 \%$, and $49.4 \%$ were classified into the HB-MO, LB-MO, HB-MNW, and LB-MNW, respectively.

\section{Comparison of characteristics among latent classes and related factors}

Age, anthropometric measurements, history of HTN or cardiocerebrovascular disease, family history of HTN, and comorbidities showed significant differences among the 4 latent classes in each sex (Table 4). Both male and female in the HB-MO had a lower mean age and a higher mean BP. The HB-MO also had a high probability of family history of HTN, and the high prevalence of stage 2 HTN and liver dysfunction ( $p<0.001$ for each). In the LB-MO, the prevalences of diabetes, renal dysfunction, and a history of cardio-cerebrovascular disease were high. In male, history of disease was highly prevalent in the LB-MNW. Anti-hypertensive drug intake was high in the LB-MO in both male and female. By comparison, a large proportion of male in the HB$\mathrm{MNW}$ and female in the HB-MO class were unaware of having HTN.

Multinomial logistic regression analysis was performed using the LB-MNW as the reference, and factors related to the latent class of HTN were evaluated (Table 5). Those who were taking anti-hypertensive drugs, and those with stage $2 \mathrm{HTN}$ were more likely to be included in the obese classese (HB-MO, LB-MO); In male, these were significantly more likely to be included in the high-risk lifestyle (HB-MNW) and the obese classes. Diabetes had similar characteristics to stage $2 \mathrm{HTN}$ as described above, and both these comorbidities were most likely to be included in the HB-MO. In female, individuals with diabetes were most likely to 
Table 2. Comparison of model fit statistics for the latent class models by sex

\begin{tabular}{|c|c|c|c|c|c|c|c|c|c|}
\hline Sex & Classes & Log-likelihood & $G^{2}$ & AIC & $\mathrm{BIC}$ & CAIC & Adjusted BIC & Entropy & df \\
\hline \multirow[t]{5}{*}{ Male } & 2 & $-431,603.15$ & $4,081.38$ & $4,111.38$ & $4,254.48$ & $4,269.48$ & $4,206.81$ & 0.72 & 112 \\
\hline & 3 & $-430,447.66$ & $1,770.39$ & $1,816.39$ & $2,035.82$ & $2,058.82$ & $1,962.73$ & 0.82 & 104 \\
\hline & 4 & $-429,942.79$ & 760.65 & 822.65 & $1,118.40$ & $1,149.40$ & $1,019.88$ & 0.83 & 96 \\
\hline & 5 & $-426,848.17$ & 534.55 & 612.55 & 984.62 & $1,023.62$ & 860.68 & 0.71 & 88 \\
\hline & 6 & $-429,671.73$ & 218.53 & 312.53 & 760.93 & 807.93 & 611.56 & 0.65 & 80 \\
\hline \multirow[t]{5}{*}{ Female } & 2 & $-344,564.29$ & $2,844.28$ & $2,874.28$ & $3,017.52$ & $3,032.52$ & $2,969.85$ & 0.75 & 112 \\
\hline & 3 & $-343,756.32$ & $1,228.34$ & $1,274.34$ & $1,493.98$ & $1,516.98$ & $1,420.89$ & 0.84 & 104 \\
\hline & 4 & $-343,462.67$ & 641.03 & 703.03 & 999.06 & $1,030.06$ & 900.54 & 0.87 & 96 \\
\hline & 5 & $-343,285.91$ & 287.51 & 365.51 & 737.94 & 776.94 & 613.99 & 0.74 & 88 \\
\hline & 6 & $-343,227.77$ & 171.24 & 265.24 & 714.06 & 761.06 & 564.69 & 0.72 & 80 \\
\hline
\end{tabular}

AIC, Akaike information criterion; BIC, Bayesian information criterion; CAIC, consistent Akaike information criterion; df, degree of freedom.

Table 3. Prevalence of lifestyle behaviors, metabolic risk, and obesity indicators, and conditional probabilities of class membership in the class mode

\begin{tabular}{|c|c|c|c|c|}
\hline \multirow{2}{*}{ Obesity status } & \multicolumn{4}{|c|}{ Latent class } \\
\hline & Class I (HB-MO) & Class II (LB-MO) & Class III (HB-MNW) & Class IV (LB-MNW) \\
\hline \multicolumn{5}{|l|}{ Male } \\
\hline Latent class prevalence (\%) & 16.9 & 32.4 & 15.3 & 35.5 \\
\hline \multicolumn{5}{|l|}{ Lifestyle behaviors } \\
\hline Uncontrolled blood pressure & 0.484 & 0.437 & 0.469 & 0.411 \\
\hline Past or current smoking & 0.829 & 0.695 & 0.842 & 0.660 \\
\hline High-risk alcohol drinking & 0.983 & 0.011 & 0.994 & 0.002 \\
\hline Insufficient physical activity & 0.441 & 0.454 & 0.405 & 0.394 \\
\hline \multicolumn{5}{|l|}{ Metabolic status } \\
\hline Metabolic risk ( $\geq 1$ component) & 0.902 & 0.878 & 0.801 & 0.762 \\
\hline \multicolumn{5}{|l|}{ Obesity status } \\
\hline Obesity $\left(\mathrm{BMI} \geq 25 \mathrm{~kg} / \mathrm{m}^{2}\right)$ & 0.937 & 0.918 & 0.229 & 0.197 \\
\hline Abdominal obesity (male: $W C \geq 90 \mathrm{~cm}$; female; $W C \geq 85 \mathrm{~cm}$ ) & 0.843 & 0.821 & 0.026 & 0.024 \\
\hline \multicolumn{5}{|l|}{ Female } \\
\hline Latent class prevalence $(\%)$ & 1.7 & 47.1 & 1.8 & 49.4 \\
\hline \multicolumn{5}{|l|}{ Lifestyle behaviors } \\
\hline Uncontrolled blood pressure & 0.510 & 0.418 & 0.326 & 0.390 \\
\hline Past or current smoking & 0.209 & 0.034 & 0.961 & 0.000 \\
\hline High-risk alcohol drinking & 0.974 & 0.000 & 0.255 & 0.026 \\
\hline Insufficient physical activity & 0.558 & 0.560 & 0.550 & 0.474 \\
\hline \multicolumn{5}{|l|}{ Metabolic status } \\
\hline Metabolic risk ( $\geq 1$ component) & 0.797 & 0.878 & 0.751 & 0.750 \\
\hline \multicolumn{5}{|l|}{ Obesity status } \\
\hline Obesity $\left(\mathrm{BMl} \geq 25 \mathrm{~kg} / \mathrm{m}^{2}\right)$ & 0.891 & 0.888 & 0.067 & 0.171 \\
\hline Abdominal obesity (male: $W C \geq 90 \mathrm{~cm}$; female: $W C \geq 85 \mathrm{~cm}$ ) & 0.872 & 0.856 & 0.041 & 0.027 \\
\hline
\end{tabular}

HP-MO, high-risk lifestyle behavior with metabolic disorder and obesity; LP-MO, low-risk lifestyle behavior with metabolic disorder and obesity; HP-MNW, high-risk lifestyle behavior with metabolic disorder and normal weight; LP-MNW, low-risk lifestyle behavior with metabolic disorder and normal weight; BMI, body mass index; WC, waist circumference.

be included in the LB-MO (odd ratio [OR], 1.57; 95\% confidence interval [CI], 1.52 to 1.61). Renal dysfunction and history of disease were more likely to occur in the LB-MO, whereas renal dysfunction was less likely to occur in the HB-MO and HB-MNW when history of disease was less likely to occur or insignificant
(OR [95\% CI] of LB-MO: renal dysfunction - male: 1.08 [1.03 to 1.13], female: 1.12 [1.07 to 1.17]; history of disease - male: 1.26 [1.21 to 1.30 ], female: 1.14 [1.10 to 1.18]). Individuals with liver dysfunction were most likely to be included in the HB-MO, and HB-NMW and LB-MO in sequence. 
Table 4. Differences in characteristics of anthropometric measurements, clinical factors, and disease history among the four latent classes

\begin{tabular}{|c|c|c|c|c|c|c|}
\hline Characteristics & $\begin{array}{c}\text { Class I } \\
\text { (HB-MO) }\end{array}$ & $\begin{array}{c}\text { Class II } \\
\text { (LB-MO) }\end{array}$ & $\begin{array}{c}\text { Class III } \\
\text { (HB-MNW) }\end{array}$ & $\begin{array}{c}\text { Class IV } \\
\text { (LB-MNW) }\end{array}$ & $p$-value & $\begin{array}{c}\text { Multiple } \\
\text { comparison }\end{array}$ \\
\hline \multicolumn{7}{|l|}{ Male } \\
\hline Age (yr) & $57.3 \pm 9.6$ & $62.5 \pm 10.8$ & $58.6 \pm 9.1$ & $64.7 \pm 10.1$ & $<0.001$ & $\mathrm{I}<\mathrm{II}<\mathrm{II}<\mathrm{IV}$ \\
\hline \multicolumn{7}{|c|}{ Anthropometric measurement } \\
\hline $\mathrm{SBP}(\mathrm{mmHg})$ & $133.5 \pm 15.0$ & $132.9 \pm 14.9$ & $132.9 \pm 15.4$ & $132.3 \pm 15.3$ & $<0.001$ & $\mid \mathrm{IV}<\mathrm{II}, \mathrm{III}<\mathrm{I}$ \\
\hline $\mathrm{DBP}(\mathrm{mmHg})$ & $84.5 \pm 10.7$ & $82.2 \pm 10.5$ & $83.7 \pm 10.8$ & $81.0 \pm 10.5$ & $<0.001$ & $\mid \mathrm{V}<\mathrm{II}<\mathrm{III}<\mathrm{I}$ \\
\hline History of HTN & & & & & & - \\
\hline No awareness & $2,867(19.0)$ & $4,625(15)$ & $4,457(24.8)$ & $6,998(18.0)$ & $<0.001$ & \\
\hline Diagnosis & $695(4.6)$ & $983(3.2)$ & $953(5.3)$ & $1,626(4.2)$ & & \\
\hline Diagnosis+medication & $11,562(76.5)$ & $25,150(81.8)$ & $12,595(70.0)$ & $30,267(77.8)$ & & \\
\hline History of disease & & & & & & - \\
\hline Overall & $934(6.2)$ & $3906(12.7)$ & $1003(5.6)$ & $4724(12.2)$ & $<0.001$ & \\
\hline Stroke & $282(1.9)$ & $1347(4.4)$ & $322(1.8)$ & $1795(4.6)$ & $<0.001$ & \\
\hline Heart disease & $698(4.6)$ & $2798(9.1)$ & 705 (3.9) & $3225(8.3)$ & $<0.001$ & \\
\hline Family history of HTN & $6,445(42.6)$ & $11,665(37.9)$ & $7,039(39.1)$ & $13,769(35.4)$ & $<0.001$ & - \\
\hline Comorbidities & & & & & & - \\
\hline Stage 2 HTN & $1,440(9.5)$ & $2,311(7.5)$ & $1,704(9.5)$ & $2,681(6.9)$ & $<0.001$ & \\
\hline Diabetes & $5,458(36.1)$ & $11,758(38.2)$ & $5,370(29.8)$ & $12,133(31.2)$ & $<0.001$ & \\
\hline Renal dysfunction & $2,333(15.4)$ & $6,955(22.6)$ & $2,253(12.5)$ & $7,525(19.4)$ & $<0.001$ & \\
\hline Liver dysfunction & $7,273(48.1)$ & $8,161(26.5)$ & 6,414 (35.6) & $5,411(13.9)$ & $<0.001$ & \\
\hline \multicolumn{7}{|l|}{ Female } \\
\hline Age (yr) & $56.0 \pm 8.7$ & $65.5 \pm 9.2$ & $59.5 \pm 9.8$ & $64.2 \pm 9.1$ & $<0.001$ & $\mathrm{I}<\mathrm{III}<\mathrm{IV}<\mathrm{II}$ \\
\hline \multicolumn{7}{|c|}{ Anthropometric measurement } \\
\hline $\mathrm{SBP}(\mathrm{mmHg})$ & $135.2 \pm 16.1$ & $134.6 \pm 15.5$ & $127.7 \pm 16.4$ & $131.5 \pm 15.6$ & $<0.001$ & $\| \mathrm{II}<\mathrm{IV}<\mathrm{II}<\mathrm{I}$ \\
\hline $\mathrm{DBP}(\mathrm{mmHg})$ & $84.7 \pm 10.8$ & $80.5 \pm 9.8$ & $79.1 \pm 11$ & $79.4 \pm 10.0$ & $<0.001$ & $\mathrm{III}, \mathrm{IV}<\mathrm{Il}<\mathrm{I}$ \\
\hline History of HTN & & & & & & - \\
\hline No awareness & $407(23.6)$ & $5891(12.9)$ & $263(16.5)$ & $8,514(15.6)$ & $<0.001$ & \\
\hline Diagnosis & $49(2.8)$ & $864(1.9)$ & $76(4.8)$ & $1,592(2.9)$ & & \\
\hline Diagnosis+medication & $1,272(73.6)$ & $39,044(85.3)$ & $1,258(78.8)$ & $44,480(81.5)$ & & \\
\hline History of disease & & & & & & - \\
\hline Overall & $64(3.7)$ & 4,027 (8.8) & $115(7.2)$ & $3,820(7.0)$ & $<0.001$ & \\
\hline Stroke & $22(1.3)$ & $1,403(3.1)$ & $50(3.1)$ & $1,395(2.6)$ & $<0.001$ & \\
\hline Heart disease & $46(2.7)$ & $2,829(6.2)$ & $73(4.6)$ & $2,622(4.8)$ & $<0.001$ & \\
\hline Family history of HTN & $856(49.5)$ & $18,509(40.4)$ & $799(50.0)$ & $24,001(44.0)$ & $<0.001$ & - \\
\hline Comorbidities & & & & & & - \\
\hline Stage 2 HTN & $199(11.5)$ & $3,164(6.9)$ & $89(5.6)$ & $3,065(5.6)$ & $<0.001$ & \\
\hline Diabetes & $401(23.2)$ & $15,427(33.7)$ & 349 (21.9) & $12,364(22.7)$ & $<0.001$ & \\
\hline Renal dysfunction & $148(8.6)$ & $9,773(21.3)$ & $227(14.2)$ & $9,296(17.0)$ & $<0.001$ & \\
\hline Liver dysfunction & $714(41.3)$ & $9,202(20.1)$ & $406(25.4)$ & $6,309(11.6)$ & $<0.001$ & \\
\hline
\end{tabular}

Values are presented as mean \pm standard deviation or number (\%).

HP-MO, high-risk lifestyle behavior with metabolic disorder and obesity; LP-MO, low-risk lifestyle behavior with metabolic disorder and obesity; HP-MNW, high-risk lifestyle behavior with metabolic disorder and normal weight; LP-MNW, low-risk lifestyle behavior with metabolic disorder and normal weight; SBP, systolic blood pressure; DBP, diastolic blood pressure; HTN, hypertension.

\section{DISCUSSION}

To identify mutually exclusive patterns in hypertensive patients, latent classes based on lifestyle, metabolic abnormalities, and obesity were analyzed, and four latent classes were distinguished for each sex. Metabolic abnormalities were included in all classes, and four classes were designated as follows: HB-MO, LB-MO, HBMNW, and the LB-MNW. In male, smoking was included in all classes, and high-risk drinking played a role as an indicator to distinguish risk lifestyle behaviors. In contrast, insufficient PA was included in all classes alone or in combination with other lifestyle factors for female, except in the LB-MNW. 
Table 5. Associations between latent class membership and demographic or clinical characteristics

\begin{tabular}{|c|c|c|c|c|}
\hline \multirow{2}{*}{ Characteristics } & \multicolumn{4}{|c|}{ Latent class } \\
\hline & Class I (HB-MO) & Class II (LB-MO) & Class III (HB-MNW) & Class IV (LB-MNW) \\
\hline \multicolumn{5}{|l|}{ Male } \\
\hline Age (per 10 yr increase) & $0.53(0.52,0.54)^{*}$ & $0.79(0.78,0.81)^{*}$ & $0.62(0.61,0.63)^{*}$ & 1.00 (reference) \\
\hline History of disease & $0.64(0.59,0.69)^{*}$ & $1.08(1.03,1.13)^{*}$ & $0.58(0.54,0.62)^{*}$ & 1.00 (reference) \\
\hline Medication for HTN & $1.50(1.43,1.58)^{*}$ & $1.43(1.37,1.49)^{*}$ & $0.99(0.95,1.04)$ & 1.00 (reference) \\
\hline Family history of HTN & $1.02(0.98,1.06)$ & $0.99(0.96,1.02)$ & $0.97(0.93,1.00)$ & 1.00 (reference) \\
\hline \multicolumn{5}{|l|}{ Comorbidities } \\
\hline Stage 2 HTN & $1.21(1.12,1.30)^{*}$ & $1.14(1.08,1.22)^{*}$ & $1.09(1.02,1.17)^{*}$ & 1.00 (reference) \\
\hline Diabetes & $1.41(1.35,1.47)^{*}$ & $1.33(1.29,1.37)^{*}$ & $1.12(1.07,1.16)^{*}$ & 1.00 (reference) \\
\hline Renal dysfunction & $0.95(0.90,1.00)$ & $1.26(1.21,1.30)^{*}$ & $0.76(0.72,0.80)^{*}$ & 1.00 (reference) \\
\hline Liver dysfunction & $4.32(4.13,4.51)^{*}$ & $2.03(1.96,2.11)^{*}$ & $2.72(2.61,2.84)^{*}$ & 1.00 (reference) \\
\hline \multicolumn{5}{|l|}{ Female } \\
\hline Age (per 10 yr increase) & $0.40(0.38,0.43)^{*}$ & $1.12(1.11,1.14)^{*}$ & $0.58(0.55,0.61)^{*}$ & 1.00 (reference) \\
\hline History of disease & $0.85(0.66,1.10)$ & $1.12(1.07,1.17)^{*}$ & $1.36(1.12,1.65)^{*}$ & 1.00 (reference) \\
\hline Medication for HTN & $1.19(1.05,1.35)^{*}$ & $1.18(1.14,1.23)^{*}$ & $1.10(0.96,1.25)$ & 1.00 (reference) \\
\hline Family history of HTN & $0.92(0.83,1.01)$ & $0.91(0.88,0.93)^{*}$ & $1.04(0.94,1.16)$ & 1.00 (reference) \\
\hline \multicolumn{5}{|l|}{ Comorbidities } \\
\hline Stage 2 HTN & $1.74(1.47,2.05)^{*}$ & $1.34(1.27,1.42)^{*}$ & $0.89(0.71,1.11)$ & 1.00 (reference) \\
\hline Diabetes & $1.15(1.02,1.29)^{*}$ & $1.57(1.52,1.61)^{*}$ & $1.00(0.89,1.13)$ & 1.00 (reference) \\
\hline Renal dysfunction & $0.70(0.58,0.83)^{*}$ & $1.14(1.10,1.18)^{*}$ & $1.06(0.92,1.23)$ & 1.00 (reference) \\
\hline Liver dysfunction & $4.42(4.00,4.90)^{*}$ & $1.90(1.83,1.97)^{*}$ & $2.32(2.06,2.61)^{*}$ & 1.00 (reference) \\
\hline
\end{tabular}

Values are presented as odds ratio ( $95 \%$ confidence interval).

HP-MO, high-risk lifestyle behavior with metabolic disorder and obesity; LP-MO, low risk lifestyle behavior with metabolic disorder and obesity; HP-MNW, high-risk lifestyle behavior with metabolic disorder and normal weight; LP-MNW, low-risk lifestyle behavior with metabolic disorder and normal weight; HTN, hypertension.

${ }^{*} p<0.05$.

Previous studies on latent class delineation in hypertensive patients have classified the cluster pattern of risk factors for HTN into 2-3 classes by risk level [12,13]. Those with uncontrolled BP level were categorized as the high-risk class; insufficient PA was also included as an important classification factor, similar to that for the female in this study. However, previous studies did not include sex-related differences, and only considered lifestyle behaviors as latent class indicators. Sex-related differences in health risk behavior patterns play an important role in the incidence and progression of chronic diseases including HTN [19]. This study identified the different lifestyle characteristics in latent classes by sex, and explained the differences in clinical health characteristics according to heterogeneous subgroups combined with metabolic abnormalities and obesity.

A previous study of lifestyle patterns in the general population reported that patterns in male primarily included drinking and smoking. Also, females were classified based on insufficient PA alone or in combination with other factors [20]. In this study, 2 out of 3 males were distributed into the low-risk lifestyle subgroups including only high-risk drinking, and $96.5 \%$ of females were distributed into the low-risk lifestyle subgroups including only insufficient PA or nothing of all factors. Hypertensive patients were mainly identified to distribute in the low-risk lifestyle behavior subgroups compared to the general population. In particular, half of females were distributed in classes without health risk behavior factors. This suggests that there is a more pronounced tendency in hypertensive female to improve their lifestyle. This finding is consistent with the reports of previous studies where female showed higher levels of lifestyle improvement to manage high BP [21,22].

Those who took anti-hypertensive drugs were more likely to be included in an obese class (HB-MO or LB-MO) regardless of their lifestyle risk level. In previous studies, the use of anti-hypertensive drugs was not related to maintaining a normal weight, but was related to obesity $[23,24]$. The relationship between anti-hypertensive drug use and obesity may be explained by the dependence on drugs in hypertensive patients. Kim \& Kong [22] suggested that anti-hypertensive drug use may cause patients to neglect weight management. In contrast, those who did not take anti-hypertensive drugs and were aware of their high BP status, showed a tendency to improve their lifestyle for managing BP [23]. Studies from Europe, Korea, and Spain have reported a difference in drinking and smoking status depending on awareness of HTN [22,25]. These findings suggest that disease awareness is important for transitioning to a healthy lifestyle and maintaining a normal weight. In this study, $16.5 \%$ of individuals did not have a HTN diagnosis and were unaware of HTN, suggesting that awareness of HTN is 
needed for effective BP management.

Independent effect of HTN has been studied by defining metabolically unhealthy normal weight (MUNW) and metabolically healthy obesity (MHO) phenotypes which take into account the major risk factors for HTN [26-29]. Kang et al. [26] and Ryoo et al. [27] (prospective studies in Korea), as well as Tian et al. [28] (cross-sectional study from China) reported that the HTN risk in the MHO and MUNW was significantly higher compared to that of the metabolically healthy normal weight. Moreover, obesity and metabolic status played an independent role in the increased risk of HTN. In contrast, the purpose of this study was to identify the clustered characteristics among hypertensive patients, and metabolic abnormalities were included in all classes. Thus, metabolically healthy obesity classes were not distinguished. In a cohort study of incidence of HTN by Lee et al. [29], many individuals in the MHO moved to metabolically unhealthy during the 8-year follow-up period, and 56.5\% of the MHO who developed HTN were metabolically unhealthy at diagnosis. These reports are in line with this study, in which metabolic abnormalities rather than obesity are emphasized in hypertensive patients. Obesity and metabolic abnormalities can be considered as independent predictors of HTN; however, these findings reflect that improving metabolic abnormalities is more important to manage HTN.

lifestyle risk behavior and obesity was independently associated with high BP. Obesity in female was associated with stage 2 HTN in prior to lifestyle risk behaviors. In comparison, it was significantly related to high BP even in the high-risk lifestyle subgroups with normal weight as well as obesity in male. Previous studies have confirmed that HTN and obesity are more closely related in female [30-32]. Faulkner \& Belin de Chantemèle [32] reported that the risk of HTN in female increased after menopause, and even before menopause, $\mathrm{BP}$ was closely related to $\mathrm{BMI}$ in obese female. Unhealthy behavior in male showed high influence than obesity on HTN. In this study, smoking was included in all latent classes of male, and high-risk lifestyles were defined according to drinking status. Thus, high-risk and low-risk lifestyles differed mainly in the drinking status. In a meta-analysis by Roerecke et al. [33], the relationship between alcohol consumption and HTN was more significant in male than in female. Choi et al. [34] analyzed the National Health and Nutrition Examination Survey data and reported that drinking significantly interfered with BP management in male. Sex-related differences was an important factor in managing the risk factors of HTN, and a differential approach was required with focus on obesity management in female, and lifestyle improvement and obesity management in male. The LBMO was significantly more likely to include a history of cardiocerebrovascular disease, awareness of HTN and comorbidities of HTN. Due to the cross-sectional design of the study, it was unclear whether the lifestyle status at the time of investigation was temporary or permanent. However, obesity was related to the incidence of comorbidities even for low-risk lifestyle status; this may complicate the treatment process.

There are several limitations in this study. First, due to the cross- sectional study design, it was not possible to identify a longitudinal relationship between HTN awareness, anti-hypertensive drug use, and lifestyle modification, and a causal relationship between lifestyle characteristics and comorbidity. Second, HTN was defined based on current BP status or survey response results rather than medical records. However, our analysis included individuals who were hypertensive by inclusion criteria, but were undiagnosed and were unaware of their HTN status. Third, Although the same sphygmomanometer models were not used in 16 examination centers, attempts were made to reduce errors in BP measurements through the standardized guideline and periodic education. Fourth, there are limits that routine national health check-up data collected and used retrospectively. The regional characteristics of the 16 check-up centers may be heterogeneous, and volunteer bias may have existed, as voluntary participants were included in the study. However, the representation of this data was proved in comparison to the national health examination data, in Noh et al. [35]. Thus, it can be seen as representing the general public. Also, as data were collected retrospectively, HTN-related factors such as duration of HTN, salt intake and period of smoking cessation were not included in the analysis $[7,21,36]$. Therefore, if these factors can be reflected in latent classes, detailed approaches such as lifestyle modification and comorbidity management strategies would be possible.

This study is meaningful as it has identified clustered characteristics including lifestyle factors, metabolic status, and obesity which are closely related to BP management, using large-scale data from hypertensive patients. This study also identified factors that distinguish the defined latent classes. Metabolic abnormalities were included in all latent classes regardless of lifestyle and obesity. Thus, an approach that considers metabolic status should be emphasized in order to effectively manage hypertensive patients. In addition to the general guidelines for managing HTN, female should manage obesity, while male should manage both obesity and their lifestyles. Furthermore, different HTN management strategies that reflect the heterogeneous characteristics of lifestyle patterns according to sex are needed.

\section{SUPPLEMENTARY MATERIALS}

Korean version is available at http://www.e-epih.org/.

\section{CONFLICT OF INTEREST}

The authors have no conflicts of interest to declare for this study.

\section{FUNDING}

None.

\section{ACKNOWLEDGEMENTS}

None. 


\section{AUTHOR CONTRIBUTIONS}

Conceptualization: EHN, SK. Data curation: SK. Formal analysis: SK. Funding acquisition: None. Methodology: SK. Project administration: EHN, SK, SC. Visualization: SK. Writing - original draft: SK. Writing - review \& editing: EHN, SK, SC.

\section{ORCID}

Suyoung Kim: http://orcid.org/0000-0003-0512-1189; Seon Cho: http://orcid.org/0000-0002-6432-5897; Eun-Hee Nah: http://orcid. org/0000-0003-0637-4364

\section{REFERENCES}

1. World Health Organization. Hypertension: 2019 [cited 2020 Jun 16]. Available from: https://www.who.int/news-room/fact-sheets/ detail/hypertension.

2. Global Burden of Metabolic Risk Factors for Chronic Diseases Collaboration. Cardiovascular disease, chronic kidney disease, and diabetes mortality burden of cardiometabolic risk factors from 1980 to 2010: a comparative risk assessment. Lancet Diabetes Endocrinol 2014;2:634-647.

3. Park SM, Lim MK, Shin SA, Yun YH. Impact of prediagnosis smoking, alcohol, obesity, and insulin resistance on survival in male cancer patients: National Health Insurance Corporation Study. J Clin Oncol 2006;24:5017-5024.

4. Appel LJ, Champagne CM, Harsha DW, Cooper LS, Obarzanek E, Elmer PJ, et al. Effects of comprehensive lifestyle modification on blood pressure control: main results of the PREMIER clinical trial. JAMA 2003;289:2083-2093.

5. Nguyen B, Bauman A, Ding D. Association between lifestyle risk factors and incident hypertension among middle-aged and older Australians. Prev Med 2019;118:73-80.

6. Krokstad S, Ding D, Grunseit AC, Sund ER, Holmen TL, Rangul $\mathrm{V}$, et al. Multiple lifestyle behaviours and mortality, findings from a large population-based Norwegian cohort study: the HUNT Study. BMC Public Health 2017;17:58.

7. Dickinson HO, Mason JM, Nicolson DJ, Campbell F, Beyer FR, Cook JV, et al. Lifestyle interventions to reduce raised blood pressure: a systematic review of randomized controlled trials. J Hypertens 2006;24:215-233.

8. Alwardat N, Di Renzo L, de Miranda RC, Alwardat S, Sinibaldi Salimei P, De Lorenzo A. Association between hypertension and metabolic disorders among elderly patients in North Jordan. Diabetes Metab Syndr 2018;12:661-666.

9. Ding D, Rogers K, van der Ploeg H, Stamatakis E, Bauman AE. Traditional and emerging lifestyle risk behaviors and all-cause mortality in middle-aged and older adults: evidence from a large populationbased Australian cohort. PLoS Med 2015;12:e1001917.

10. Loef $\mathrm{M}$, Walach $\mathrm{H}$. The combined effects of healthy lifestyle behaviors on all cause mortality: a systematic review and meta-analysis. Prev Med 2012;55:163-170.
11. Ingledew DK, Hardy L, Cooper CL. Latent class analysis applied to health behaviours. Pers Individ Dif 1995;19:13-20.

12. Ghanbari J, Mohammadpoorasl A, Jahangiry L, Farhangi MA, Amirzadeh J, Ponnet K. Subgroups of lifestyle patterns among hypertension patients: a latent-class analysis. BMC Med Res Methodol 2018;18:127.

13. Trivedi RB, Ayotte BJ, Thorpe CT, Edelman D, Bosworth HB. Is there a nonadherent subtype of hypertensive patient? A latent class analysis approach. Patient Prefer Adherence 2010;4:255-262.

14. Mulè G, Calcaterra I, Nardi E, Cerasola G, Cottone S. Metabolic syndrome in hypertensive patients: an unholy alliance. World J Cardiol 2014;6:890-907.

15. Korean Society of Hypertension. Essentials of 2018 Korean Society of Hypertension guideline for management of hypertension [cited 2020 Jun 16]. Available from: http://www.koreanhypertension.org/reference/guide mode $=$ read\&idno $=4246$ (Korean).

16. Hong Y, Chun S, Yun M, Asante LS, Chu C. A study of high-risk drinking patterns among generations based on the 2009 Korea National Health and Nutrition Examination Survey. Osong Public Health Res Perspect 2014;5:46-53.

17. World Health Organization. Physical activity; 2018 [cited 2020 Jun 18]. Available from: https://www.who.int/news-room/factsheets/detail/physical-activity.

18. Nylund KL, Asparouhov T, Muthén BO. Deciding on the number of classes in latent class analysis and growth mixture modeling: a Monte Carlo simulation study. Struct Equ Modeling 2007;14:535569.

19. Varì R, Scazzocchio B, D’Amore A, Giovannini C, Gessani S, Masella R. Gender-related differences in lifestyle may affect health status. Ann Ist Super Sanita 2016;52:158-166.

20. John U, Hanke M, Freyer-Adam J. Health risk behavior patterns in a national adult population survey. Int J Environ Res Public Health 2018;15:873.

21. Hu H, Li G, Arao T. Prevalence rates of self-care behaviors and related factors in a rural hypertension population: a questionnaire survey. Int J Hypertens 2013;2013:526949.

22. Kim Y, Kong KA. Do hypertensive individuals who are aware of their disease follow lifestyle recommendations better than those who are not aware? PLoS One 2015;10:e0136858.

23. Akbarpour S, Khalili D, Zeraati H, Mansournia MA, Ramezankhani A, Fotouhi A. Healthy lifestyle behaviors and control of hypertension among adult hypertensive patients. Sci Rep 2018;8:8508.

24. Neutel CI, Campbell N; Canadian Hypertension Society. Changes in lifestyle after hypertension diagnosis in Canada. Can J Cardiol 2008;24:199-204.

25. Gee ME, Bienek A, Campbell NR, Bancej CM, Robitaille C, Kaczorowski J, et al. Prevalence of, and barriers to, preventive lifestyle behaviors in hypertension (from a national survey of Canadians with hypertension). Am J Cardiol 2012;109:570-575.

26. Kang YM, Jung CH, Jang JE, Hwang JY, Kim EH, Park JY, et al. The association of incident hypertension with metabolic health and obesity status: definition of metabolic health does not matter. Clin Endocrinol (Oxf) 2016;85:207-215. 
27. Ryoo JH, Park SK, Oh CM, Choi YJ, Chung JY, Ham WT, et al. Evaluating the risk of hypertension according to the metabolic health status stratified by degree of obesity. J Am Soc Hypertens 2017;11:20-27.

28. Tian S, Xu Y, Dong H. The effect of metabolic health and obesity phenotypes on risk of hypertension: a nationwide population-based study using 5 representative definitions of metabolic health. Medicine (Baltimore) 2018;97:e12425.

29. Lee SK, Kim SH, Cho GY, Baik I, Lim HE, Park CG, et al. Obesity phenotype and incident hypertension: a prospective communitybased cohort study. J Hypertens 2013;31:145-151.

30. Fujita M, Hata A. Sex and age differences in the effect of obesity on incidence of hypertension in the Japanese population: a large historical cohort study. J Am Soc Hypertens 2014;8:64-70.

31. Sampson UK, Edwards TL, Jahangir E, Munro H, Wariboko M, Wassef MG, et al. Factors associated with the prevalence of hypertension in the southeastern United States: insights from 69,211 blacks and whites in the Southern Community Cohort Study. Circ Cardiovasc Qual Outcomes 2014;7:33-54.
32. Faulkner JL, Belin de Chantemèle EJ. Sex differences in mechanisms of hypertension associated with obesity. Hypertension 2018; 71:15-21.

33. Roerecke M, Tobe SW, Kaczorowski J, Bacon SL, Vafaei A, Hasan OS, et al. Sex-specific associations between alcohol consumption and incidence of hypertension: a systematic review and meta-analysis of cohort studies. J Am Heart Assoc 2018;7:e008202.

34. Choi HM, Kim HC, Kang DR. Sex differences in hypertension prevalence and control: analysis of the 2010-2014 Korea National Health and Nutrition Examination Survey. PLoS One 2017;12: e0178334.

35. Noh Y, Jeong HE, Kim HJ, Ko H, Nah EH, Shin JY. The multi-institutional health screening records database of South Korea: description and evaluation of its characteristics. Yonsei Med J 2019; 60:1216-1222.

36. Halimi JM, Giraudeau B, Vol S, Cacès E, Nivet H, Tichet J. The risk of hypertension in men: direct and indirect effects of chronic smoking. J Hypertens 2002;20:187-193. 